\section{SMGrsup}

\section{SM Dentistry Journal}

Article Information

Received date: May 13, 2016

Accepted date: Oct 30, 2016

Published date: Nov 14, 2016

*Corresponding authors

Abdullah SE, Izmir KatipCelebi University, Faculty of Dentistry, Department of Periodontology, Izmir, Turkey, Tel: +902323524040, Email: ertugrulseckin@yahoo.com

Distributed under Creative Commons CC-BY 4.0

Keywords Peripheral giant cell granuloma; Guided tissue regeneration; Chronic periodontitis

\title{
Peripheral Giant Cell Granuloma Treatment with Guided Tissue Regeneration: A Case Report
}

\author{
Selin Genc and Abdullah Seckin Ertugrul ${ }^{*}$ \\ Izmir Katip Celebi University, Faculty of Dentistry, Department of Periodontology Izmir, Turkey
}

\section{Abstract}

Peripheral giant cell granuloma is uncommon benign tumor of oral cavity. A 62 years old female patient presented with an easily bleeding mass localized in the upper jaw. In clinical examination $11 \mathrm{~mm}$ diameter gingival lesion was seen. Flap surgery was planned to access the periodontal defect and remove the lesion. Bone graft and membrane was used to regenerate periodontium. There was no recurrence in three month. In this case; possible etiology was presence of periodontitis and poor oral hygiene. Periodontal treatment and proper oral hygiene are the key factors for prevention of the recurrence after excision the lesion.

\section{Introduction}

The peripheral giant cell reparative granuloma has been described for many years in literature under a variety of names. It also named with peripheral giant cell tumor and giant cell epulis [1]. The etiology of Peripheral Giant Cell Granuloma (PGCG) is not clear. It can be considered an over exuberant local response of tissue to injury. PGCG is known as asymptomatic, hyperplastic lesion of the attached gingiva or alveolar mucosa. Clinically lesion located on the gingival or edentulous ridge and the most common site is posterior area. Mostly, lesions are asymptomatic but the chief complaint is bleeding due to trauma. Treatment of PGCG consists, removal of the lesion and eliminating traumatic factors [2].

\section{Case Presentation}

Sixty two years old female patient was referred to Izmir Katip Celebi University (IKCU) Dentistry Faculty. Patient's oral hygiene was not good and the periodontal diagnosis was moderate chronic periodontitis. The lesion was located on the attached gingiva of maxillary first and second molar region. Clinical appearance was bluish red, smooth surface and $11 \mathrm{~mm}$ diameter gingival lesion (Figure 1). Probing depth was $7 \mathrm{~mm}$ on the distal vestibular surface of the first molar. At the first appointment, scaling was completed and proper oral hygiene instruction was given. Also a biopsy material was taken from the lesion and sent to the pathology department of the IKCU. According to the pathology report the diagnosis was PGCG. Reevaluation was revealed that dimension of the lesion and $7 \mathrm{~mm}$ probing depth was not change. An appointment for the complete removal of the lesion and flap surgery was set. After the complete removal of the granulation tissue, two wall bone defect was seen (Figure 2). Also small radiolucent area is shown in radiographic analysis (Figure 3). Xenograft bone graft (Tutobone; Tutogen Medikal, Germany) was used to fill the defect (Figure 4). After grafting, resorbable membrane (Lyomesh Neuro vr; Audio Technologies, Italy) was used. Three month after surgery showed no recurrence (Figure 5).

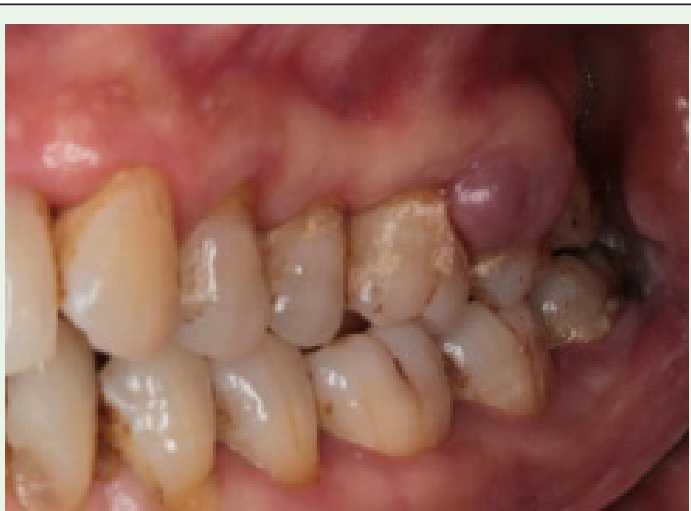

Figure 1: Clinical appearance was bluish red, smooth surface and $11 \mathrm{~mm}$ diameter gingival lesion. 


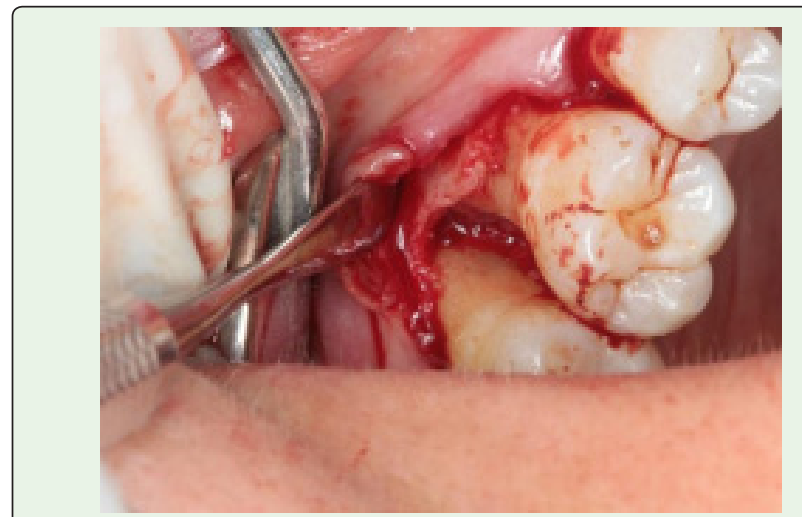

Figure 2: After the complete removal of the granulation tissue, two wall bone defect was seen.

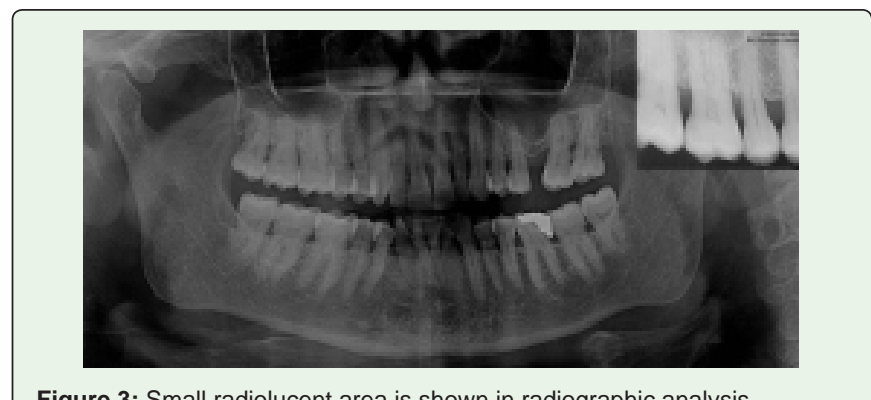

Figure 3: Small radiolucent area is shown in radiographic analysis.

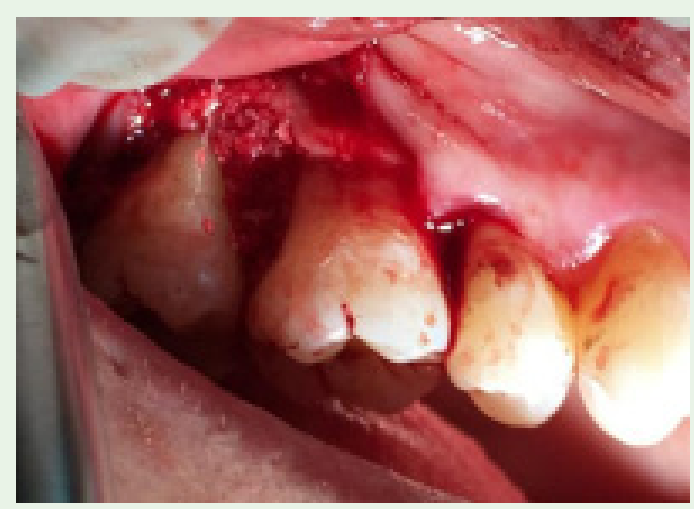

Figure 4: Xenograft bone graft and collagen membrane were used to fill the defect.

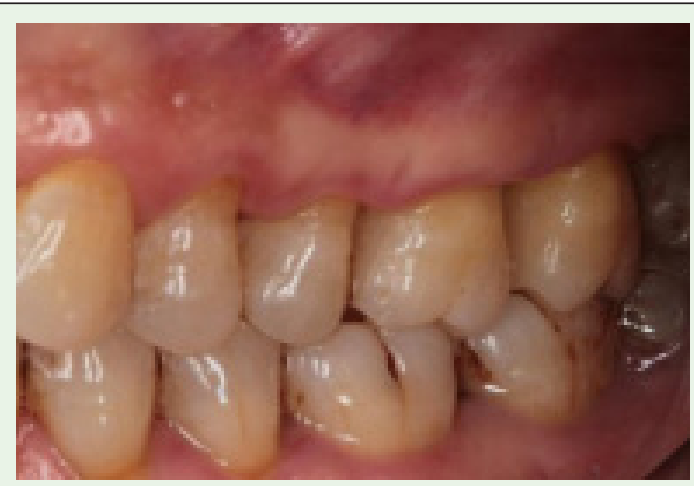

Figure 5: Clinical appearance of three month after surgery.

\section{Discussion}

There is a theory that claims that the proliferation of giant cells associated with resorption of deciduous teeth has been implicated in the development of giant cells lesions. But this theory has some weakness because those lesions also may see in edentulous areas [3]. In 1954, Barnier and Cahn suggested that trauma may be a major etiologic factor. In this study peripheral giant cell reparative granuloma cases surveyed and they found that 53\% cases have trauma history. It has been suggested that an injury to the periodontal ligament and gingiva initiating a reactive hyperplastic response in the periosteum plays a role [4]. The main traumatic factor is extraction of teeth. Other traumatic causes are periodontal treatment, chronic infection, and irritation from dentures, improper use of oral hygiene products, non-dental trauma due to accidents, periodontitis and presence of calculus formation, food impaction. Hormonal disturbances and primer hyperparathyroidism also has been known to other possible etiologic factors [5]. In this case, patient's periodontal diagnosis was generalizing moderate chronic periodontitis. According to clinical findings, calculus formation and presence of chronic periodontitis may be the reasons of chronic trauma.

PGCG is known as an asymptomatic, benign, hyperplastic lesion of the attached gingiva or alveolar mucosa. This rare lesion thought to arise from connective tissue or the periosteum of the alveolar ridge in response to injury [3]. It affects all ages but the pick frequency in the fourth and sixth decades of life and occurs in the mandible more often than in the maxilla [6]. Although it affects both sexes, most studies have shown predilection for females [7]. Other studies failed to show any sex differences [8]. In this case, patient was 62 years old female and the patient profile is consistent with the current literature. PGCG occurs more often in posterior mandibular area and the size of the lesion vary $2 \mathrm{~mm}$ to $5 \mathrm{~mm}$. In contrast to the literature, in this case the location of the lesion was posterior maxillar area. Possible explanations are the presence of trauma due to calculus formation in the posterior maxilla and patient's inability to use interdental cleaning products due to hard access this area.

It is believed that the lesion may originate from osteoclasts or macrophages. Its clinical importance lies in the fact that extensive lesions may result in advanced bone resorption, which can lead to esthetic concerns or even tooth loss $[8,9]$.

Clinically lesion located on the gingival or edentulous ridge and the most common site is posterior area. Size of the lesion ranged $2 \mathrm{~mm}$ to $5 \mathrm{~mm}$ [2]. Lesions can be sessile or pedunculated, rubbery too soft on palpation. Ulceration may occur secondary to trauma and resulting in a focal yellow zone caused by the fibrin clot overlying the ulcer [9]. Histological, PGCG differs from other hyperplastic lesions with the presence of multinuclear giant cells. Possible reason of presence of multinuclear giant cells is reaction of unknown stimuli. Studies suggested that the origin of the multinuclear giant cells is macrophages and osteoclasts. Primer histopathology feature of PGCG is florid granulation tissue. Lesion characterized by highly cellular mass with abundant multinucleated giant cells, inflammatory cells, hemosiderin deposits, hemorrhage, mature bone and osteoid. Chronic inflammatory cells and neutrophils are also seen under the ulcerated area [9]. In this case, lesion was located on the attached gingiva of the first and second maxillary molar teeth. Clinically, it was dark red, smooth surface, pedunculated lesion which is soft on palpation [10]. 
Treatment of PGCG consists, complete removal of the lesion and eliminating the local traumatic factors. Excision should be containing a border of normal tissue for preventing the risk of recurrence After excision of the lesion, bone and soft tissue defects can be left. Hard and soft tissue grafting procedures should be considered for the rehabilitation. In this case, biopsy was taken before complete removal of the lesion. After definite diagnosis, lesion was removed with containing a border of normal tissue for preventing recurrence. During our three month follow up, no recurrence was seen.

\section{References}

1. Gottsegen R. Peripheral Giant cell reparative granuloma following periodontal surgery. J Periodontol. 1962; 33: 190-194.

2. Bodner L, Peist M, Gatot A, Fliss DM. Growth potential of peripheral giant cell granuloma. Oral Surg Oral Med Oral Pathol Oral Radiol Endod. 1997: 83; 548-551.

3. Shields J. Peripheral giant-cell granuloma: A review. J Ir Dent Assoc. 1993; 40: $39-41$.
4. Bernier JL, Cahn LR. The peripheral giant cell reparative granuloma. J Am Dent Assoc. 1954; 49: 141-148.

5. Burkes EJ, White RP. A peripheral giant-cell granuloma manifestation of primary hyperparathyroidism: report of case. J Am Dent Assoc. 1989; 118: 62-64.

6. Motamedi MHK, Eshghyar N, Jafari SM, Lassemi E, Navi F, Abbas FM Peripheral and central giant cell granulomas of the jaws: a demographic study. Oral Surg Oral Med Oral Pathol Oral Radiol Endod. 2007; 103: e39-e43.

7. Eversole L, Rovin S. Reactive lesions of the gingiva. J Oral Pathol Med. 1972 1: $30-38$

8. Giansanti J, Waldron C. Peripheral giant cell granuloma: review of 720 cases. J Oral Maxillofac Surg. 1969; 27: 787-791.

9. Sahingur SE, Cohen RE, Aguirre A. Esthetic management of peripheral giant cell granuloma. J Periodontol. 2004; 75: 487-492.

10. Lev R, Moses O, Holtzclaw D, Tal H. Esthetic treatment of peripheral giant cell granuloma using a subepithelial connective tissue graft and a splitthickness pouch technique. J Periodontol. 2010; 81: 1092-1098. 